\title{
CAPÍTULO 04: GESTÃO PÚBLICA DO TURISMO: UMA ANÁLISE DO PROCESSO DE GESTÃO DA AGENDA CULTURAL DA CIDADE DE OLINDA (PE)
}

\author{
CAPÍTULO 04: GESTIÓN PÚBLICA DEL TURISMO: UN ANÁLISIS DEL \\ PROCESO DE GESTIÓN DE LA AGENDA CULTURAL DE LA CIUDAD DE \\ OLINDA (PE)
}

\author{
CHAPTER 04: PUBLIC TOURISM MANAGEMENT: AN ANALYSIS OF THE \\ MANAGEMENT PROCESS OF THE CULTURAL AGENDA OF THE CITY OF \\ OLINDA (PE)
}

Leandro Neves Bispo de Lima ${ }^{1}$; Isabela Rebeca Maria Melquíades de Araújo ${ }^{2}$; Iraneide Pereira da Silva ${ }^{3}$

DOI: https://doi.org/10.31692/978-65-88970-03-4.53-72

\begin{abstract}
RESUMO
A Agenda Cultural da cidade de Olinda (PE) é a principal ferramenta de compilação e divulgação de programações culturais que ocorrem no município. Tais eventos têm relevância estratégica para a atividade turística local, principalmente no que tange à sazonalidade. O presente trabalho se propõe a lançar um olhar crítico sobre a gestão desta ferramenta, a partir da ótica da gestão pública. Tem-se por objetivo geral: analisar o processo de gestão da Agenda Cultural de Olinda. Metodologicamente, buscou-se coletar informações do poder público municipal, representado pela diretoria de patrimônio e cultura e de turismo, a respeito da ferramenta, por meio de entrevistas. Para análise, utilizou-se a técnica de análise de conteúdo. A discussão fundamentou-se nas concepções acerca da administração de Chiavenato (2003) e Sobral e Peci (2008) e acerca da administração pública de Bresser-Pereira (1997), Gomes e Oliveira (2010), Motta (1979) e Secchi (2009). A partir da análise feita, foram identificados alguns gargalos no processo de gestão, que vão desde o seu planejamento ao seu controle, indicando que o processo de captação de informações para a agenda é deficitário, sua distribuição centrada em poucos canais e que não se tem um controle das métricas de sucesso. Além disso, observou-se que o engessamento dos procedimentos no setor público pode ter influência sobre o quadro enfrentado, tanto na entrega da Agenda Cultural como produto de promoção turística do destino, como também na dificuldade da relação entre a Prefeitura Municipal de Olinda e os agentes culturais da cidade, importantes stakeholders do processo de gestão.
\end{abstract}

Palavras-Chave: Administração pública, turismo, cultura.

\section{RESUMEN}

La Agenda Cultural de la ciudad de Olinda (PE) es la principal herramienta para la recopilación y difusión de los programas culturales que se desarrollan en el municipio. Estos eventos tienen relevancia estratégica para la actividad turística local, principalmente en lo que respecta a la estacionalidad. Este trabajo se propone dar una mirada crítica a la gestión de esta herramienta, desde la perspectiva de la gestión pública. El objetivo general es analizar el proceso de gestión de la Agenda Cultural Olinda. Metodológicamente, se buscó recabar información del gobierno municipal, representado por la dirección de patrimonio y cultura y turismo, sobre la herramienta, a trayés de entrevistas. Para el análisis, utilizó la técnica de análisis de contenido. La discusión se basó en las concepciones sobre la administración de Chiavenato (2003) y Sobral y Peci (2008) y sobre la administración pública de Bresser-Pereira (1997), Gomes y Oliveira (2010), Motta (1979) y Secchi

\footnotetext{
${ }^{1}$ Graduando em Gestão de Turismo, Instituto Federal de Pernambuco - IFPE, Inbl@discente.ifpe

${ }^{2}$ Bacharelanda em administração, Universidade Federal de Pernambuco - UFPE, isabela.mel

Bolsista do Programa de Educação Tutorial, financiado pelo FNDE.

${ }^{3}$ Doutora em Administração, Instituto Federal de Pernambuco - IFPE, iraneidepereir
} 
(2009). A partir del análisis realizado, se identificaron algunas dificultades en el proceso de gestión, que van desde su planificación hasta su control, indicando que el proceso de captación de información para la agenda es deficiente, su distribución centrada en unos pocos canales y que no existe control de métricas de éxito. Además, se observó que el enlucido de trámites en el sector público puede incidir en la situación que atraviesa, tanto en la entrega de la Agenda Cultural como producto de promoción turística del destino, como en la dificultad de la relación entre el Municipio de Olinda y el agentes culturales de la ciudad, actores importantes en el proceso de gestión.

Palabras Clave: Administración pública, turismo, cultura.

\section{ABSTRACT}

The Cultural Agenda of the city of Olinda (PE) is the main tool for compiling and disseminating cultural programs that take place in the municipality. Such events have strategic relevance for the local tourist activity, mainly with regard to seasonality. This work proposes to take a critical look at the management of this tool, from the perspective of public management. The general objective is to analyze the management process of the Olinda Cultural Agenda. Methodologically, we sought to collect information from the municipal government, represented by the heritage and culture and tourism directorate, regarding the tool, through interviews. For analysis, we've used the content analysis technique. The discussion was based on the conceptions about the administration of Chiavenato (2003) and Sobral and Peci (2008) and about the public administration of Bresser-Pereira (1997), Gomes and Oliveira (2010), Motta (1979) and Secchi (2009). From the analysis made, some difficulties in the management process were identified, ranging from its planning to its control, indicating that the process of capturing information for the agenda is deficient, its distribution is centered in a few channels and that there is no track of success metrics. In addition, it was observed that the plastering of procedures in the public sector may have an influence on the situation faced, both in the delivery of the Cultural Agenda as a tourist promotion product of the destination, as well as in the difficulty of the relationship between the Municipality of Olinda and the cultural agents in the city, important stakeholders in the management process.

Keywords: Public administration, tourism, culture.

\section{INTRODUÇÃO}

A atividade turística é um dos mais importantes setores da economia mundial, dado o grande crescimento no número de viajantes internacionais ao longo das últimas décadas, chegando, de acordo com a Organização Mundial do Turismo - UNWTO, sigla em inglês (2018, p. 12) , a 1,3 bilhão de pessoas em trânsito ano de 2017 (UNWTO, 2017).

A partir de dados do Conselho Mundial de Viagens e Turismo - WTTC, sigla em inglês (2020, p. 01), pode-se observar que o turismo representou 10,3\% do PIB mundial em 2019, tendo a América Latina contribuído com 8,7\%, da receita gerada, o que equivale a US\$ 336 bilhões - somente o Brasil (2020, p. 01) gerou US\$ 139.9 bilhões, equivalente a 7,7\% do PIB nacional naquele ano. É apontado ainda que $94 \%$ dos viajantes no país são domésticos e $89 \%$ estavam viajando com propósitos de lazer (WTTC, 2019).

No âmbito nacional, utilizando a ferramenta de extração de dados do Instituto de Pesquisa Econômica Aplicada - IPEA, podemos verificar, através do uso de contextos, 
dimensões e métricas ${ }^{6}$, que o número de empregos em atividades caracteristicamente turísticas (ACTs) chegou a 2.1 milhões de ocupações em dezembro de 2018, último dado apresentado na plataforma (IPEA, 2020, s/p).

De acordo com o Mapa do Turismo7 ${ }^{7}$, elaborado pelo Ministério do Turismo, o Estado de Pernambuco está dividido em 16 regiões turísticas, que compreendem um total de 103 municípios, onde cada região compreende um conjunto de municípios com potencial para trabalhar um ou mais segmentos. A cidade de Olinda está inserida na região História e Mar, junto às cidades de Cabo de Santo Agostinho, Fernando de Noronha, Ipojuca, Jaboatão dos Guararapes e Recife, formando a mais importante região do estado, devido a sua localização, infraestrutura e concentração de atrativos.

A fim de visualizar a situação de Olinda no cenário estadual, consulta-se o Plano Estratégico de Turismo de Pernambuco (2008-2020), que define Recife, Olinda e Jaboatão como o Polo Região Metropolitana dentro das regiões turísticas. Destes, Recife e Olinda "são tratadas conjuntamente por propiciar uma experiência de visitação única e integrada" (EMPETUR, 2008 p. 3), além de serem considerados municípios indutores de desenvolvimento. De acordo com a Base de Dados do Estado de Pernambuco (CONDEPE/FIDEM, 2016, pp. 01-02), o município conta com uma economia baseada, majoritariamente, no setor de serviços, junto a uma participação minoritária da indústria e uma percentagem irrisória da agropecuária.

Às vistas da importância econômica representada pela atividade, Barretto (2015), descreve o turismo, no âmbito comercial, como um produto elaborado a partir dos recursos naturais ou culturais, sejam estes materiais ou simbólicos, juntos aos equipamentos turísticos e seus serviços, como hospedagem e alimentação. Este produto, uma vez projetado, é ofertado em mercado e adquirido pelos seus interessados.

Tendo em vista os pontos citados anteriormente, podemos concluir que Olinda, com seus 485 anos de existência, representa um produto turístico de grande relevância no cenário regional, sendo reconhecida nacional e internacionalmente pelo seu patrimônio históricocultural, a exemplo do título de Patrimônio Cultural Brasileiro, concedido pelo Instituto do Patrimônio Histórico e Artístico Nacional - IPHAN em 1968, e o título e Patrimônio

6 Contextos: "Dimensão da ocupação no Turismo", Dimensões: "Ano/Mês de referência e Todas as ACTs" e Métricas: "Número de ocupações".

${ }_{7}$ Ministério do Turismo. Mapa. Disponivel em: <http://www.mapa.turismo.gov.br/mapa/init.html\#/home>. Acesso em: 04 de agosto de 2020. 
Histórico e Cultural da Humanidade concedido pela Organização das Nações Unidas para Educação, Ciência e Tecnologia (UNESCO, sigla em inglês). Além disto, também é palco de diversas manifestações culturais relevantes, como do Frevo, tombado pela UNESCO como Patrimônio Cultural Imaterial da Humanidade ${ }^{8}$, assim como o Maracatu Nação ${ }^{9}$, o Cavalo Marinho $^{10}$ e o Caboclinho ${ }^{11}$, listados como Patrimônio Cultural do Brasil pelo IPHAN.

Olinda, cidade rica em manifestações culturais, tem a Agenda Cultural como principal meio de divulgação de seus eventos culturais. Esta ferramenta, gerida por órgãos públicos municipais encontrava-se disposta em material físico, através de uma unidade impressa para consulta nos Centros de Atendimento ao Turista - CATs, e digitalmente, através de uma mailing list $\mathrm{e}$, posteriormente, pelo site Olinda Turismo ${ }^{12}$ com frequência semanal.

No entanto, no material divulgado pela Agenda Cultural, foram observadas, de forma empírica, algumas inconsistências e superficialidades - o conteúdo era repetitivo e limitado além de falhas na execução e manutenção dos cronogramas de divulgação. Essas observações originaram os questionamentos para esta pesquisa, quais sejam, como se dá o processo de gestão da agenda? Quais os gargalos neste processo de gestão?

Tendo em vista as problemáticas citadas, tem-se, através deste trabalho, o objetivo de analisar o processo de gestão da Agenda Cultural de Olinda. Faz-se útil analisar a construção e ação desta ferramenta a fim de entender como e quando se estabelecem as dificuldades de sua gestão, visualizando suas inconsistências, visando propor melhorias na operacionalização das atividades.

Para a construção desta pesquisa, utilizou-se de revisão bibliográfica acerca da temática abordada, além de pesquisa de campo por meio de instrumentos de coleta, no formato de roteiro semi estruturado para a realização das entrevistas e de análise dos dados obtidos pela análise de conteúdo (BARDIN, 2016; FRANCO, 2003). Ressalta-se que o conteúdo aqui apresentado é um excerto dos resultados obtidos durante pesquisa realizada para o Trabalho de Conclusão de Curso dos mesmos autores defendido em 2019, que teve por objetivo analisar a gestão da Agenda Cultural da cidade de Olinda e propor alternativas ao modelo.

\footnotetext{
${ }^{8}$ Título concedido no ano de 2012.

9 Título concedido no ano de 2014.

10 Título concedido no ano de 2014

11 Título concedido no ano de 2016.

12 Olinda Turismo - Agenda Cultural. Disponível em: <https://www.olinda.pe.gov.br/turismo/agendacultural//>. Acesso em: 30 de agosto de 2020.
} 


\section{FUNDAMENTAÇÃO TEÓRICA}

Neste item são apresentados os fundamentos teóricos que dão base à discussão sobre o processo de gestão da Agenda Cultural de Olinda, objeto deste estudo.

\section{A administração}

É seguro dizer que, hoje, a administração se tornou uma das mais importantes atividades humanas. Conforme Chiavenato (2003, p. 10), "o esforço cooperativo do homem é a base fundamental da sociedade". E nisso, a administração atua como ferramenta essencial, uma vez que sua tarefa básica é viabilizar realizações, por meio da ação conjunta de pessoas, de forma eficaz e eficiente. A administração se preocupa em interpretar objetivos e transformá-los em ação, por meio do planejamento, da organização, da direção e do controle de recursos.

Antes de ser compreendida como ciência, a administração já era praticada, seja nas organizações militares ou eclesiásticas, por exemplo. No entanto, foi apenas no começo do século XX que a chamada administração científica, primeira teoria administrativa comumente estudada, surgiu, capitaneada por Frederick Taylor, engenheiro mecânico que se ateve à questão da ordenação das tarefas.

Importa notar que as teorias da administração se valem do caráter cumulativo da construção do conhecimento e também da gradativa abrangência deste. Assim, outros teoristas, pressionados pelos desafios organizacionais de suas épocas, desenvolveram diferentes teorias com ênfases distintas, além das tarefas, sendo estas: estrutura, pessoas, ambiente, tecnologia e competitividade (CHIAVENATO, 2003).

Para fins desta pesquisa, consideraremos que a administração tem quatro funções principais: planejamento, organização, direção e controle.

Para Sobral e Peci (2008, p. 132), “o planejamento é a função da administração responsável pela definição dos objetivos da organização e pela concepção de planos que integram e coordenam suas atividades". Compõem o planejamento a análise dos ambientes interno e externo, a identificação dos recursos necessários e disponíveis e, a partir disso, a definição dos objetivos da organização. Sua necessidade surge ao passo que o ambiente em que as organizações se inserem se torna cada vez mais instável. Assim, para se manter a longo prazo, é necessário ter um norte e as estratégias para chegar até ele.

Já a organização é aquela função constituída na "distribuição de trabalho, recursos e autoridade pelos membros da organização" (SOBRAL; PECI, 2008, p. 166). É nessa etapa em que se define quem vai fazer o quê, os recursos que serão utilizados nos processos e quem tem 
autoridade sobre quem. Também são estabelecidos os mecanismos de comunicação entre as partes.

A direção se detém nas relações interpessoais e na relação entre os indivíduos e a organização, sendo responsável por alinhar todos aos objetivos previstos no planejamento. Essa responsabilidade se traduz em práticas como o provimento de boas condições de trabalho, de ferramentas de comunicação entre os setores, da resolução de conflitos, entre outros (SOBRAL; PECI, 2008, p. 200).

O processo de controle é responsável pela avaliação e, se necessária, a correção das atividades executadas pela organização, observados os seus objetivos, de forma contínua. É na etapa do controle que se avalia a efetividade, conforme a seguir:

O controle tem duas atribuições essenciais: o monitoramento das atividades, comparando o desempenho real com o planejado, e a correção de qualquer desvio significativo, caso se conclua que as atividades estão sendo executadas de tal forma que não conduzam ao alcance dos objetivos definidos. (SOBRAL; PECI, 2008, p. 231)

Importa lembrar que tais funções não estão postas de forma linear no processo administrativo. Apesar de o planejamento ser uma fase primária, este pode ser revisitado em caso de necessidade. Além disso, as funções de direção e controle são de atividade constante.

As funções da administração elencadas, básicas e fundamentais, se adequam a quaisquer âmbitos administrativos, sejam eles em esfera privada ou pública. No entanto, há que se considerar que a administração pública tem peculiaridades próprias, conforme a seguir.

\section{Modelos de administração pública}

Assim como a ciência administrativa, a administração pública passou por diferentes fases. Tais fases correspondem a diferentes momentos históricos que demandaram modelos administrativos que atendessem às necessidades que o contexto lhes impunha. Para fins deste estudo, vamos versar sobre três grandes modelos básicos: patrimonialista, burocrático e gerencial.

A administração patrimonialista é caracterizada majoritariamente pela não distinção entre o que é público e o que é privado. Derivada das monarquias absolutistas, tem-se o aparelho do Estado como uma extensão dos domínios do soberano (GOMES; OLIVEIRA, 2010).

Tal modelo entra em decadência ao passo que se torna incompatível com a realidade, diante da atuação de dois atores principais: o capitalismo, que por sua vez exige separação entre Estado e mercado; e a democracia, na qual a sociedade civil deve se distinguir do 
Estado, enquanto o controla (BRESSER-PEREIRA, 1996). Assim sendo, busca-se um modelo alternativo que supere as dores inerentes ao modelo patrimonialista - a exemplo do nepotismo e da corrupção como regra.

A alternativa ao modelo patrimonialista tem seu cerne na compreensão Weberiana de legitimidade, sob a ótica da sociologia política. Weber entende que as relações de dominação se mantêm, também, pela crença na legitimidade destas (AMORIM, 1996, p. 119). De modo que a sustentação destas relações, estão intimamente ligadas à percepção da sua legitimidade. Entre os tipos de legitimidade descritos por Weber - carismática, tradicional e racional-legal tem-se a última como aquela que será expressa pela burocracia.

Com isso, chegamos ao modelo burocrático de administração pública, que baseado na legitimação racional-legal, busca a eficiência ao se firmar em regulamentos explícitos universalmente aplicáveis. Chiavenato (2003) lista as características da burocracia, segundo Weber, das quais destacamos: caráter legal das normas e regulamentos; caráter racional e divisão do trabalho; impessoalidade nas relações; hierarquia de autoridade; rotinas e procedimentos padronizados; competência técnica e meritocracia; profissionalização dos participantes.

O modelo baseado na burocracia, porém, apresenta disfunções características. Um dos pilares para sua sustentação é a previsibilidade. As detalhadas normas e procedimentos só teriam eficácia diante de um cenário conhecido e previsível. Tal pilar se mostrou insustentável ao longo do tempo. Segundo Bresser-Pereira (1996, p. 11), o problema da eficiência torna-se essencial ao passo que o Estado, antes preocupado com garantir propriedades e contratos, passa a assumir um crescente número de serviços sociais e papéis econômicos.

As disfunções do modelo apresentam um quadro de estagnação. Conforme abordado por Merton (1966, apud MOTTA, 1979), a internalização por parte dos funcionários dos preceitos burocráticos estimula o conformismo, o conservadorismo e o tecnicismo. Isto se traduz na prática em um aumentado apego às normas e procedimentos e na despersonalização nos relacionamentos com o público, a quem a burocracia deveria servir. Ou seja, os meios importam mais do que os fins. Motta $(1979$, p. 17) resume:

A submissão à norma, que passa de meio a fim em si mesma, gera, a nível da organização, um deslocamento de objetivos. Em termos das "virtudes" do burocrata, leva à rigidez de comportamento e à dificuldade no trato com o público, a quem a burocracia deve atender.

A ineficácia do modelo burocrático se acentua diante não só da complexidade da atuação do Estado, mas de fatores exógenos a este, como as inovações tecnológicas e a globalização. Diante desse cenário, surge, então, o modelo gerencial de administração 
pública, dedicado à excelência administrativa e ao foco no cidadão, incorporando aspectos da iniciativa privada.

O modelo gerencial de administração pública pode se traduzir em: administração pública gerencial (APG), governo empreendedor (GE) e governança pública (GOMES e OLIVEIRA, 2010, p. 115). Enquanto os dois primeiros compartilham semelhantes valores e características, sempre vinculados à efetividade da gestão, o último trata da relação da administração com o ambiente externo.

Para Secchi (2009, p. 354), a administração pública gerencial é "um modelo normativo pós-burocrático para a estruturação e a gestão da administração pública baseado em valores de eficiência, eficácia e competitividade". A APG baseia-se na interpretação positiva dos seguintes valores: "eficiência e alocação racional de recursos, limitação do desperdício, simplicidade e clareza" (SECCHI, 2009, p. 355).

Uma importante característica da administração pública gerencial diz respeito ao seu controle que, diferentemente do modelo burocrático, se dá nos resultados. Bresser-Pereira (1996), apoiado em Osborne e Gaebler, apresenta os princípios desse modelo, dos quais destacamos: pressuposto da confiança limitada, controle por resultados e administração voltada para o atendimento do cidadão. Tais princípios se traduzem em menor rigidez quanto aos procedimentos a fim de alcançar os resultados e atender às demandas dos cidadãos.

Retomando a lógica da legitimidade trazida anteriormente, mas agora sob a ótica da organização, temos que no modelo burocrático a legitimidade se dá pela atenção às normas, enquanto no modelo gerencial, se dá pelo alcance de resultados. Ou seja, enquanto o primeiro se atém aos meios, o último se atém aos fins. Trata-se de uma virada de paradigma, quando se deixa de se olhar essencialmente para dentro e passa-se à busca pelo melhor atendimento ao usuário cidadão.

\section{Governança pública e turismo}

Conforme mencionado anteriormente, o modelo gerencial se vale, também, governança pública para a sua composição. Fundamental à análise aqui proposta, o conceito de governança pública é compreendido como:

Uma nova geração de reformas administrativas e de Estado, que têm como objeto a ação conjunta, levada a efeito de forma eficaz, transparente e compartilhada, pelo Estado, pelas empresas e pela sociedade civil, visando uma solução inovadora dos problemas sociais e criando possibilidade e chances de um desenvolvimento futuro e sustentável para todos os participantes (LÖFFLER, 2001, p. 202, apud SANTOS: PINTO; CÁSSIA, 2017, p. 3).

É baseada neste entendimento que a gestão pública assume a essencial função de 
fomentar, junto aos stakeholders - comunidades, empreendimentos e outros - a promoção da atividade turística de modo a propiciar o desenvolvimento sustentável. Este fomento se dá, essencialmente, por meio da promoção de políticas públicas. Para Lohmann e Panosso Netto (2008, p. 121), pode-se compreender política pública de turismo como "o direcionamento dado pelo governo federal, estadual, municipal e regional para o desenvolvimento da atividade turística".

Uma das políticas públicas de relevância estratégica para a atividade turística, figurando inclusive entre as políticas públicas do governo federal, são os eventos. Isto porque, historicamente, os eventos estão no cerne do deslocamento turístico (MATIAS, 2013). Há exemplos vindos dos Jogos Olímpicos na Grécia Antiga, das peregrinações medievais, das feiras pós revolução industrial e mesmo dos megaeventos musicais que acontecem na contemporaneidade.

Os eventos têm objetivos e formatos diversos, mas de forma geral um evento "tem como característica principal propiciar uma ocasião extraordinária ao encontro de pessoas, com finalidade específica, a qual constitui o "tema" principal do evento e justifica a sua realização" (GIACAGLIA, 2003, p. 3). Dentre as classificações, existem os eventos culturais, sendo aqueles que "englobam as manifestações temporárias, enquadradas ou não na definição de patrimônio, incluindo-se nessa categoria os eventos gastronômicos, religiosos, musicais, de dança, de teatro, de cinema, exposições de arte, de artesanato e outros" (BRASIL, 2010, p. 17).

Melo, Araújo-Maciel e Figueiredo (2015, p. 260) argumentam que "uma localidade turística deve reconhecer que os eventos são ferramentas de auxílio no fomento à atividade do turismo". Estudos realizados em diferentes partes do país apresentam os eventos como uma ferramenta para o turismo, seja no fomento da atividade e desenvolvimento local, a exemplo daquele realizado por Melo, Araújo-Maciel e Figueiredo (2015) sobre o Festival Folclórico de Parintins (AM); como ferramenta para a captação de clientes em meios de hospedagem, a exemplo do trabalho de Mondo e Costa (2010) sobre a contribuição dos eventos para a hotelaria em Santa Catarina; ou como indutor de benefícios vários, conforme a análise da evolução do turismo de eventos promovida por Montes e Coriolano (2003), que apresenta eventos como a Oktoberfest (SC), a Paixão de Cristo (PE) e o Maceió Fest (AL) e suas externalidades positivas para as suas sedes.

Amparados nessas compreensões, identificamos como importante o papel assumido pela Agenda Cultural de Olinda como o principal meio de divulgação institucional dos eventos, especialmente os culturais, que acontecem na cidade. Em uma análise própria, que 
compreendeu o período de 31 de agosto a 13 de dezembro de 2018, pudemos contabilizar um total de 477 eventos registrados, fixos e esporádicos, com ocorrência em 6 regiões da cidade, como podemos visualizar abaixo:

Figura 1 - Mapa das localidades abrangidas em relação à extensão da cidade

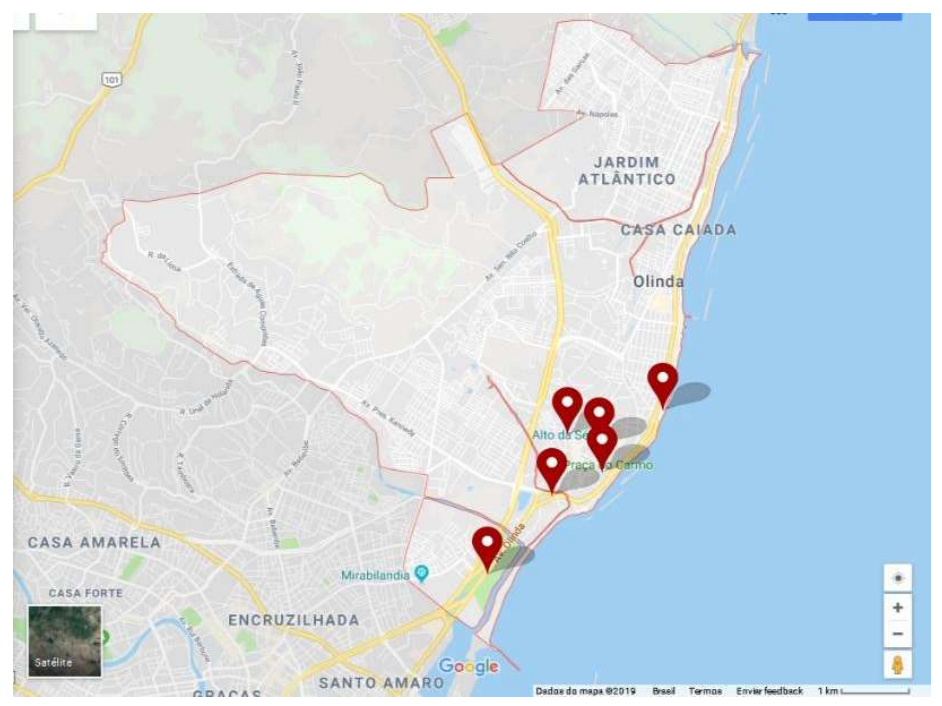

Fonte: Site Google Maps (mapa), acrescido de modificação própria.

Pôde-se observar a proximidade e repetição dos eventos registrados, em pontos próximos ao Sítio Histórico da cidade, diferentemente do restante do município. A produção desta ferramenta de divulgação de relevância estratégica, hipoteticamente, envolve diferentes atores, sendo os principais a gestão pública municipal, os agentes de cultura da cidade e o público local e visitante. Assim, compreendemos que a manutenção e a otimização desta ferramenta têm efeitos sobre a saúde das atividades relacionadas ao turismo em Olinda.

\section{METODOLOGIA}

A fim de atender ao objetivo proposto, desenvolveu-se uma pesquisa de natureza qualitativa, uma vez que o nosso objeto de estudo é de ordem social e não tende à quantificação (LIEBSCHER, 1998 apud DIAS, 2000). Assim, foram empregados procedimentos interpretativos para compreensão dos dados, em detrimento de representações numéricas (SUTTON, 1993 apud DIAS, 2000). Além disso, a pesquisa tem caráter exploratório, pois pretende levantar informações iniciais e apresentar uma visão geral acerca do objeto estudado (GIL, 2008).

Buscou-se compreender e estabelecer uma discussão inicial sobre como se dá o 
processo de gestão da agenda cultural da cidade de Olinda, nosso objeto de pesquisa, a partir da ótica da gestão pública do turismo. Nossos sujeitos são, portanto, os gestores públicos das áreas de cultura, turismo e comunicação, envolvidos neste processo.

Para embasar teoricamente esta pesquisa, utilizou-se revisão bibliográfica acerca dos temas abordados por meio da consulta de livros e artigos. Também se realizou análise documental, especialmente no campo legal, pois a gestão pública é regulada por estas normas.

A coleta dos dados se valeu da ferramenta entrevista, que, segundo Gil (2008, p. 115), é "a técnica em que o investigador se apresenta frente ao investigado e lhe formula perguntas, com o objetivo de obtenção dos dados que interessam à investigação". Optou-se pelo tipo de entrevista informal, aquela que tem um nível mínimo de estruturação (GIL, 2008). Assim, tinha-se um roteiro semiestruturado de entrevista, mas que poderia ser adaptado de acordo com o andamento da interlocução, com o objetivo de obter as informações necessárias.

As transcrições das entrevistas foram submetidas à análise de conteúdo, que, segundo Bardin (apud FRANCO, 2003, p. 20), "pode ser considerada como um conjunto de técnicas de análises de comunicações, que utiliza procedimentos sistemáticos e objetivos de descrição do conteúdo das mensagens". Observado o nosso objetivo, as entrevistas foram analisadas a partir de categorias que correspondiam às quatro funções da administração, a priori, planejamento, organização, direção e controle. A posteriori, surgiu uma nova categoria de análise: o incentivo.

Para fins desta pesquisa, nos propusemos a realizar entrevistas com a Diretoria de Turismo, a Diretoria de Patrimônio e Cultura e a Secretaria de Comunicação da Prefeitura Municipal de Olinda. No entanto, por uma série de incompatibilidades de datas e horários, a entrevista com a Secretaria de Comunicação foi inviabilizada, assim, apenas as visões das Diretorias de Turismo e Patrimônio e Cultura serão aqui abordadas. As entrevistas foram realizadas entre novembro de 2018 e fevereiro de 2019, presencialmente, nas dependências das diretorias. Em comum acordo entre as partes, as entrevistas foram gravadas para posterior transcrição análise. Os resultados desta análise serão expostos e discutidos a seguir.

\section{RESULTADOS E DISCUSSÃO}

Considerando a fundamentação anteriormente discutida, a presente pesquisa identificou um processo a ser otimizado da gestão pública no que tange a divulgação dos eventos culturais da cidade, o que gera impacto sobre a promoção de Olinda como destino 
turístico. Os servidores consultados demonstraram ter ciência do cenário em que se encontravam e identificaram os obstáculos para melhora, notadamente no que se refere aos processos estudados, conforme segue:

\section{Planejamento}

No discurso da diretoria de turismo, notou-se que a gestão conhece as ferramentas do planejamento e seus componentes - plano diretor de turismo, plano de marketing e pesquisa de marketing, além de reconhecer a sua importância. Porém, na prática, estes instrumentos não são implementados.

A gente tem uma debilidade grande[...]: uma falta de pesquisa de marketing. Nós não temos um plano de marketing da cidade. Inclusive, esse plano de marketing, ele é previsto no nosso plano diretor de turismo. (Técnico - Representante da Diretoria de Turismo)

O plano de marketing é a principal ferramenta de gestão para a promoção de um destino. É na sua construção que são identificadas a oferta e a demanda do destino, e que se estabelecem os objetivos e resultados esperados, dos quais se originam as estratégias e a operacionalização. Conforme Dias e Cassar (2005):

O plano de marketing pode ser visto como um processo de melhoria das ações de marketing em relação aos ambientes interno e externo, partindo da avaliação prévia dos elementos ambientais e definindo estratégias e ações específicas para cada caso (DIAS; CASSAR, 2005, p. 178).

Sem um plano de marketing, a promoção torna-se deficitária, o que pode influenciar diretamente sobre a sustentabilidade do destino turístico - principalmente quando levamos em conta o fator da sazonalidade. Para o Ministério do Turismo do Brasil (2010, p. 15), eventos culturais, ao promoverem aspectos singulares, são excelentes instrumentos para reduzir os efeitos da sazonalidade. A gestão pública, de acordo com a nossa análise, reconhece que há uma relação de complementaridade entre os eventos e a vivência turística na cidade.

A gente sabe que os eventos e o patrimônio estão muitos ligados. Assim, as pessoas não vêm necessariamente apenas para o evento, ela vem pra Olinda... Os eventos é muito... É algo que complementa. (Técnico - Representante da Diretoria de Turismo)

De volta aos instrumentos de planejamento, observamos que um dos motivos para a não implementação do que é previsto no plano diretor de turismo, é a limitação fínanceira, conforme apontado nos trechos a seguir:

A gente 'tá com planejamento de suporte financeiro. Buscar suporte financeiro pra justamente o que eu falei: investir no marketing promocional, num material promocional físico. (Técnico - Representante da Diretoria de Turismo) 
Este aspecto é complementado e corroborado pela declaração do respondente entrevistado, como segue:

A divulgação que a gente tem é só virtual, a gente não tem material promocional, a prefeitura não tá com recursos. Os editais que financiavam essas atividades 'tão bem escassos ultimamente. Com o corte de despesas federais, a gente não tem recurso pra divulgar os eventos. (Técnico - Representante da Diretoria de Turismo)

A partir disto, observa-se uma séria debilidade na promoção do turismo na cidade de Olinda, que é reconhecida pela gestão municipal, e que por sua vez alega não dispor dos recursos financeiros necessários para dar encaminhamento às demandas.

\section{Organização}

Além da falta de recursos financeiros, relatou-se falta de pessoal para tratar das atividades específicas de promoção, o que nos remete à função da administração chamada de organização, que trata da distribuição do trabalho e também da comunicação entre as partes.

Assim, pudemos identificar junto à gestão os principais processos relacionados à promoção do destino. No campo digital, tais processos se dão a partir da integração de esforços entre as diretorias de turismo, cultura e patrimônio e da secretaria de comunicação. E que as mídias institucionais utilizadas são: site oficial, página no Facebook e perfil no Instagram.

Temos um site, foi lançado recentemente, [...] que tá sendo alimentado constantemente. Esse alimento... Essa alimentação, melhor dizendo, não é feito por nós. Nós alimentamos a questão dos atrativos, dos restaurantes, dos bares, essa parte, mas a parte da agenda cultural, quem alimenta é a secretaria de comunicação, bem como a fanpage do Facebook. Antigamente era a gente, na última gestão, mas nessa nova gestão eles tomaram pra si essa função. Toda semana, então a gente pega os eventos e passa pra eles. (Técnico - Representante da Diretoria de Turismo)

O site de que se fala é o Olinda Turismo, lançado em 2018. Nele, estão informações sobre serviços úteis ao turista, compilados dos eventos fixos da cidade, atrativos, meios de hospedagem, restaurantes e afins, além da agenda cultural.

A partir da análise, pudemos, também, desenhar o processo de produção da Agenda Cultural da cidade, que pode ser dividido em três fases: captação das informações, construção da agenda e distribuição.

A fase inicial corresponde à captação das atividades que serão realizadas na semana em questão, uma vez que a publicação da agenda é semanal. Essa captação se dá das seguintes formas: a) envio voluntário das informações por parte daqueles que querem promover seus eventos na publicação, via e-mail; ou b) envio voluntário via WhatsApp, por meio da lista de transmissão criada pela diretoria de turismo; ou c) pesquisa, por parte da equipe de turismo, 
nas redes sociais dos estabelecimentos, grupos nestas redes, e até por telefone para levantar informações; ou d) envio por e-mail, por parte da diretoria de cultura, das programações das quais tem ciência e das que são organizadas pela mesma.

Em seguida, a agenda propriamente dita é construída. A Diretoria de Turismo compila estas informações e as insere em um layout - feito previamente pela Secretaria de Comunicação. O produto final é um quadro constando do nome, data, hora e local do evento, junto a um telefone para contato, conforme figura 2, abaixo.

Figura 2 - Agenda Cultural de Olinda

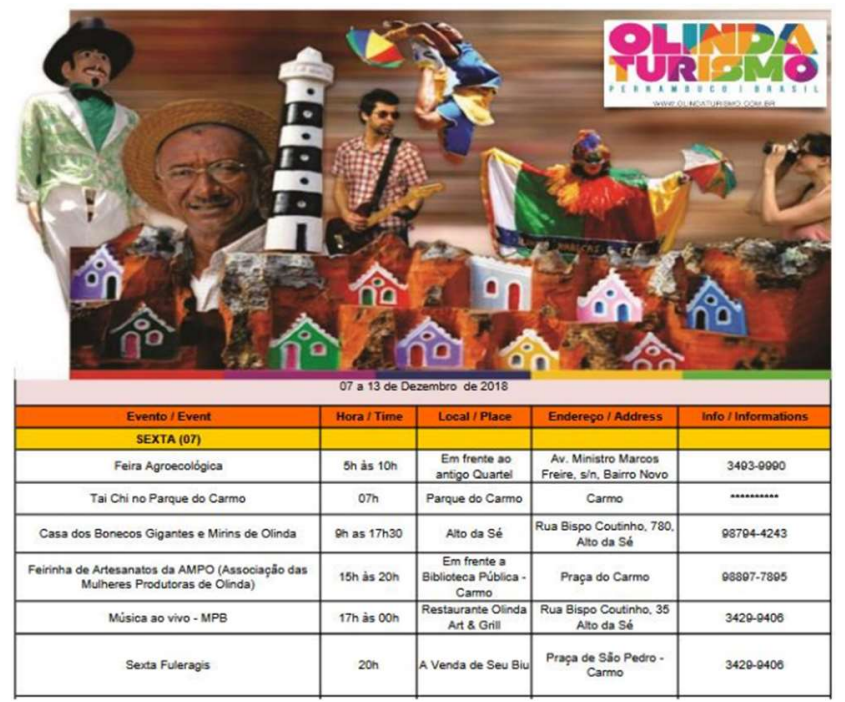

Fonte: Prefeitura Municipal de Olinda (Site, 2018) ${ }^{13}$

Por fim, há a distribuição. A diretoria de turismo se responsabiliza por enviar a agenda, em formato PDF - um arquivo de texto - via e-mail para uma mailing list de mais de duas mil pessoas, e para os Centros de Atendimento ao Turista - CAT.

[...] A gente envia toda sexta, né, pro mailing list da gente, tem mais de 2 mil contatos. Enviamos essa agenda para os atendimentos do turismo, pra que as pessoas tenham informação e poder fornecer. (Representante da Diretoria de Turismo)

Segundo o entrevistado, os colaboradores dos CAT são orientados a pedir o e-mail dos visitantes que queiram receber a agenda, para que sejam adicionados a esta mailing list. Fora esta, não existe nenhuma forma de se inscrever para o recebimento. Já a secretaria de comunicação se responsabiliza por inserir este mesmo arquivo no site Olinda Turismo (ilustrado na figura 2, anteriormente) com um breve resumo das atividades, além de fazer esporádicas publicações a respeito na página da Prefeitura de Olinda no Facebook.

\footnotetext{
${ }^{13}$ Nova consulta à ferramenta foi realizada em 2020, ano da redação deste artigo, e identificou-se que a página dedicada à Agenda Cultural no site Olinda Turismo não mais apresenta os arquivos aquí descritos, mas uma aplicação do Google Calendar, que serve como agenda. Apesar da mudança recente de formato, a agenda do site encontra-se vazia e não apresenta nenhuma programação cultural. Ressaltamos que a coleta de dados para esta pesquisa foi realizada no período entre os anos de 2018 e 2019.
} 
Não foi relatado nenhum processo de controle na gestão desta ferramenta. Por se tratar de um ambiente virtual, algumas métricas para $e$-mail marketing como taxa de crescimento da lista, taxa de abertura de e-mails, taxa de cliques e taxa de descadastro ou marcação de spam poderiam ser avaliadas, mas, neste caso, não são.

\section{[...] Na agenda cultural, essa que é enviada por e-mail, não tem nenhuma} mensuração. (Representante da Diretoria de Turismo)

Apesar disso, existe o canal "fale conosco" no site, que pode ser usado para feedback com relação a quaisquer assuntos relacionados ao turismo na cidade.

A partir dessas constatações, podemos fazer algumas inferências. Primeiro, falta ao processo de captação de informações maior uniformização, com um único canal institucional e procedimentos claros e padronizados para o envio de informações mais ricas. Outro ponto seria a estrutura visual da agenda, que é pouco intuitiva e não permite que se pesquise eventos por tipo ou linguagem, o que compromete a experiência do usuário. Quanto à distribuição, o processo é centrado essencialmente nos Centros de Atendimento ao Turista - CATs, e, ao ignorar as demais formas de divulgação pode ter seu alcance limitado. Por último, como não há um processo de controle, não é possível saber com clareza se a ferramenta está sendo eficaz, de modo que permanece turvo o caminho para a otimização.

\section{Direção}

Em nossa análise, encontramos algumas divergências nos discursos dos representantes da gestão municipal, que sinalizam falhas na comunicação entre as diretorias: enquanto o representante da Diretoria de Turismo sinaliza que há o contato, os representantes da Diretoria de Patrimônio e Cultura afirmam desconhecer a existência do mesmo no momento, ainda que o elo existisse no passado. Segue-se um claro exemplo de ruído comunicacional:

[...] A gente tem o contato com a pessoa de Cultura que manda pra gente, por email, os eventos que estão acontecendo, que eles organizaram ou que eles têm conhecimento. [...] Eles mandam pra gente, e a gente insere. (Técnico Representante da Diretoria de Turismo)

Em contrapartida, a fala da outra secretaria envolvida indica outra visão sobre a comunicação estabelecida entre as secretarias, como segue:

É isso que a gente diz, assim, não tá tendo essa comunicação. A gente não sabe se Turismo tá fazendo por conta, se não tá fazendo. Pelo menos daqui a gente não tem mandado informação para turismo... E por qual motivo a gente também não sabe. Se porque não tá tendo mais, se é porque eles se viram por lá então eles não têm interesse em saber informação daqui para lá, são várias nuances. (Técnica Representante da Diretoria de Patrimônio e Cultura)

Ainda que a departamentalização dos processos por grupos funcionais seja algo real e 
necessário, deve-se levar em conta que os departamentos são interdependentes e, portanto, devem estar cientes das atividades uns dos outros. A divergência evidenciada nos leva a inferir que não existe um fluxo de comunicação bem definido entre os setores, a fim de direcionar as atividades das diretorias para o desenvolvimento da Agenda Cultural. Fatores como estes facilmente resultam em ineficiência que, na prática, podem ser visualizadas pela presença clara de ruído comunicacional na elaboração de trabalhos que, presumidamente, devem ser de execução integrada.

\section{Controle}

Os processos supracitados nos levam a um caminho, e este deve ser monitorado através dos processos de controle. A gestão do destino Olinda demonstra, conforme relatado pelos servidores ouvidos em ambas as diretorias envolvidas, falta de solidez em suas ações de direção e controle, uma vez que as ações de planejamento e organização são implementadas e dissolvidas ao longo das gestões, como ocorreu com a Agenda e o Cadastro Cultural ${ }^{14}$, implementadas pela então Secretaria de Patrimônio e Cultura, no mandato dos prefeitos Luciana Santos (2001 - 2008) e Renildo Calheiros (2009 - 2017), respectivamente.

Porque nós aqui, da Secretaria de Cultura, Diretoria de Cultura, nós tínhamos, né, um agendamento cultural, uma agenda cultural funcionando, e deixou também de existir isso, né. Por uma questão de

Esta descontinuidade é também indicada pela outra representante entrevistada, conforme depoimento ora exposto:

[...] também se faz necessário que tenhamos um cadastro cultural ativo... todo nosso cadastro foi jogado... foi totalmente por água abaixo. $O$ trabalho feito pela gestão passada, que a gente não tem registro nenhum sobre isso ... e nosso cadastro cultural está desativado desde a última gestão, do segundo mandato de Renildo Calheiros. (Técnico - Representante da Diretoria de Patrimônio e Cultura)

Esta descontinuidade pode ser percebida pelos agentes de cultura e figurar como fator do distanciamento entre eles e a gestão. Com relação a isso, no campo da Diretoria de Cultura, o discurso revela fatores de interesse e descuido, já no do campo de Turismo, vemos que a ruptura se deu por outros motivos: falta de pessoal e recursos.

Eu acho que eles nem percebem que podem ter essa ligação com a gente, o que é algo que tem que ser construido, né. Porque assim... eu passei quatro anos afastado daqui e era eu quem fazia essa captação, e agora que a gente tá retomando esse... essa iniciativa, da gente ir atrás, deles reconhecerem quem é a pessoa lá dentro que tá cuidando disso. (Técnico - Representante da Diretoria de Turismo)

14 No ano de 2020, com as dificuldades provocadas pela pandemia da COVID-19, a Prefeitura de Olinda reativou o cadastro cultural da cidade. A inscrição é feita por meio de um formulário online. Não recorremos à administração municipal para compreender como se dá o tratamento destes novos dados, pois não competia ao objetivo desta pesquisa. 
Outro fator que parece corroborar para o distanciamento entre esses atores é a questão da frustração com a falta de ações e do fomento à cultura. Conforme relato abaixo, estes artistas se sentem negligenciados, sem a possibilidade de recorrer à figura da prefeitura para a resolução de quaisquer de seus problemas, enfraquecendo estes laços.

Quando ele [o artista] entra aqui, ele entra com uma dificuldade, ele entra com um problema, ele quer solução. Ele se afasta, ele desaparece, ele fica triste, ele não cria, ele não participa de eventos... (Técnico - Representante da Diretoria de Patrimônio e Cultura)

Então, às vezes, eles se distanciam da gente porque eles ficam com a frustração de que "eu levei meu problema pro cara, ele sabe, mas até hoje ele não resolveu”. Ai passa-se um, dois, dez anos, e ninguém resolve. (Técnica - Representante da Diretoria de Patrimônio e Cultura)

Santos, Pinto e Cássia (2017, p. 3) argumentam que a confiança é determinante para o estabelecimento da cooperação e para o estabelecimento de uma rede, fator importantíssimo no campo da governança pública. O que se constata aqui, porém, é que a relação entre os agentes culturais e a gestão pública de cultura está fragilizada por diversos fatores. A recuperação desse elo depende de uma grave articulação política e administrativa, no sentido de identificar, compreender e atender as demandas dos agentes culturais. E isso perpassa a implementação de políticas públicas que tenham impacto sobre o campo cultural, e consequentemente sobre o campo do turismo.

\section{CONCLUSÕES}

Ao analisar os resultados obtidos à luz do problema da nossa pesquisa identificamos como se dá o processo de gestão da agenda cultural da cidade de Olinda. Tal processo se dá em três fases, sendo todas elas, a partir da nossa interpretação, passíveis de otimização. As melhorias devem atentar aos gargalos identificados, a saber: a não padronização da aquisição de informações, a limitação na formatação e na distribuição da ferramenta e também a falta do processo de controle para garantir a sua eficácia.

Apesar dos esforços de delinear modelos e fases históricas, observa-se que a administração pública traz consigo aspectos incorporados dos diferentes estágios experimentou. Neste estudo, notou-se que a rigidez produzida pela burocracia, que limitava contratações e acesso a recursos financeiros, foi um dos fatores observados que prejudicava a eficiência da atividade. No entanto, esta mesma burocracia, ou seja, este sistema administrativo baseado em normas legais, delegava formalmente as responsabilidades de cada ator, apesar destas não serem totalmente cumpridas na prática. 
Outra observação importante foi a falta de coordenação das atividades que dependiam de diferentes secretarias, mas que não tinham papéis ou formas de comunicação bem definidos. Como vimos, isso gera impacto na construção do produto, a agenda cultural, também na relação que o poder público tem com os agentes de cultura, que se torna cada vez mais frágil. A falta de confiança no poder público pode gerar problemas no reconhecimento de sua legitimidade.

Conquanto reconhecemos a necessidade de modernização e adequação aos dias atuais, incorporando práticas da iniciativa privada, concordamos que a administração pública não deve fazer com que o objetivo maior do Estado seja suplantado, que é o atendimento do interesse público, preservados os valores democráticos.

Com esta pesquisa, esperamos fornecer as informações iniciais para o enfrentamento das dificuldades encontradas na administração pública na cidade de Olinda, com vistas à otimização da promoção de eventos culturais no município. Para o futuro, julgamos importante que se avalie esta mesma questão, mas sob a ótica dos agentes de cultura, enquanto principais stakeholders da gestão cultural da cidade, para que sua percepção seja analisada.

\section{REFERÊNCIAS}

AMORIM, Aluízio Batista de. Os desdobramentos da dominação legal na atualidade a partir de Max Weber. Orientador: Edmundo Lima de Arruda Júnior. 1996. 209 f. Dissertação (Mestrado em Direito) - Universidade Federal de Santa Catarina, Florianópolis (SC), 1996. Disponível em: <https://core.ac.uk/download/pdf/30386587.pdf >. Acesso em 11 ago. 2020.

BARDIN, Laurence. Análise de conteúdo. São Paulo: Edições 70, 2016.

BARRETTO, Margarita. Cultura e turismo: Discussões contemporâneas. Campinas, SP: Papirus, 2015.

BRASIL. Ministério do Turismo. Turismo Cultural: orientações básicas. 3 ed. Brasília: Ministério do Turismo, 2010.

BRESSER-PEREIRA, Luiz Carlos. Da administração burocrática à gerencial. Revista do Serviço Público, v. 47, n. 1, 1996.

CHIAVENATO, Idalberto. Introdução à teoria geral da administração: uma visão abrangente da moderna administração das organizações. 7 ed. Rio de Janeiro: Elsevier, 2003.

CONDEPE/FIDEM - Base de Dados do Estado. Perfil Municipal: Olinda. Disponível em: $<$ http://www.bde.pe.gov.br/ArquivosPerfilMunicipal/OLINDA.pdf $>$. Acesso em: 23 jun. 2019.

DIAS, Cláudia. Pesquisa qualitativa - características gerais e referências. Maio, 2000. 
Disponível

em:

$<$ http://www.paulorosa.docente.ufms.br/metodologia/Textos/Dias_Pesquisa_Qualitativa.pdf $>$. Acesso em 28 jul. 2020.

DIAS, Reinaldo. CASSAR, Maurício. Fundamentos do marketing turístico. São Paulo: Pearson Prentice Hall, 2005.

EMPRESA PERNAMBUCANA DE TURISMO - EMPETUR. Síntese da pesquisa sobre o perfil socioeconômico do turista - Recife 2006-2008. 2008. Disponível em: $<$ http://www2.setur.pe.gov.br/c/document_library/get_file?p_1_id=22093\&folderId=30717\&n ame=DLFE-1979.pdf $>$. Acesso em: 04 out. 2020.

FRANCO, Maria Laura Puglisi Barbosa. Análise de Conteúdo. Brasília: Plano Editora, 2003.

GIACAGLIA, Maria Cecília. Organização de eventos: teoria e prática. São Paulo: Pioneira Thomson Learning, 2003.

GIL, Antonio Carlos. Métodos e técnicas de pesquisa social. $6^{\mathrm{a}}$ ed. São Paulo: Atlas, 2008.

GOMES, Maria Lucineide Serpa; OLIVEIRA, Francisco Correia de. Modelos organizacionais de administração pública: um estudo dos aspectos da realidade cearense na estrutura de referência das reformas do Estado. Revista de Ciências da Administração, v. 12, n. 28, p. 105-126, 2010.

INSTITUTO DE PESQUISAS ECONÔMICAS APLICADAS - IPEA. Extrator de Dados. Disponível em: <https://www.ipea.gov.br/extrator/>. Acesso em: 04 ago. 2020.

LOHMANN, Guilherme; PANOSSO NETTO, Alexandre. Teoria do turismo: conceitos, modelos e sistemas. São Paulo: Aleph, 2008.

MATIAS, Marlene. Organização de eventos: procedimentos e técnicas. Barueri: Manole, 2013.

MELO, José Jailson Medeiros de; ARAÚJO-MACIEL, Ana Paula; FIGUEIREDO, Silvio José de Lima. Eventos Culturais como estratégia de fomento do turismo: análise do Festival Folclórico de Parintins (AM). Revista Brasileira de Ecoturismo, São Paulo, v.8, n.2, mai/ago 2015, pp. 251-272.

MINISTÉRIO DO TURISMO - MTUR. Mapa. Disponível em: $<$ http://www.mapa.turismo.gov.br/mapa/init.html\#/home>. Acesso em: 04 ago. 2020.

Turismo Cultural: orientações básicas. 3 ed. Brasília:

Ministério do Turismo, 2010.

MONDO, Tiago Savi; DA COSTA, Jane Iara Pereira. Hotelaria em Santa Catarina: a contribuição dos eventos. Rosa dos Ventos, v. 2, n. 1, p. 31-44, 2010.

MONTES, Valéria Alves. Coriolano, Luzia Neide M. T. Turismo de eventos: promoções e parcerias no Brasil. Turismo em Análise, v. 14, n. 1, p. 40-64, maio 2003.

MOTTA, Fernando C. Prestes. Controle social nas organizações. Revista de Administração de Empresas, v. 19, n. 3, p. 11-25, 1979. Disponível em: $<$ https://www.scielo.br/pdf/rae/v19n3/v19n3a02.pdf>. Acesso em 10 ago. 2020 
OLINDA. Olinda Turismo. Disponível em: $<$ https://turismo.olinda.pe.gov.br/>. Acesso em 02 jul. 2020.

SANTOS, Leonardo Tadeu dos; PINTO, Juliana de Fátima; CÁSSIA, Maria Gabriela de. Redes de cooperação e governança pública: o caso do mapeamento cultural de Belo Horizonte. Competência. Porto Alegre, v. 10, n. 2, dez. 2017.

SECCHI, Leonardo. Modelos organizacionais e reformas da administração pública. Revista de Administração Pública, v. 43, n. 2, p. 347-369, 2009.

SOBRAL, Filipe; PECI, Alketa. Administração: teoria e prática no contexto brasileiro. Pearson Prentice Hall, 2008.

UNITED NATIONS WORLD TOURISM ORGANIZATION - UNWTO. Annual Report 2017. p. 12. Disponível em: <https://www.e-unwto.org/doi/book/10.18111/9789284419807>. Acesso em 23 jul. 2020.

WORLD TRAVEL \& TOURISM COUNCIL - WTTC. Brazil. 2019. Disponível em: < https://wttc.org/Research/Economic-

Impact/moduleId/704/itemId/77/controller/DownloadRequest/action/QuickDownload>. Acesso em: 09 set. 2020.

Global Economic Impact \& Trends 2020. Disponível em:

$<$ https://wttc.org/Research/Economic-

Impact/moduleId/1445/itemId/91/controller/DownloadRequest/action/QuickDownload>. Acesso em 30 ago. 2020. 